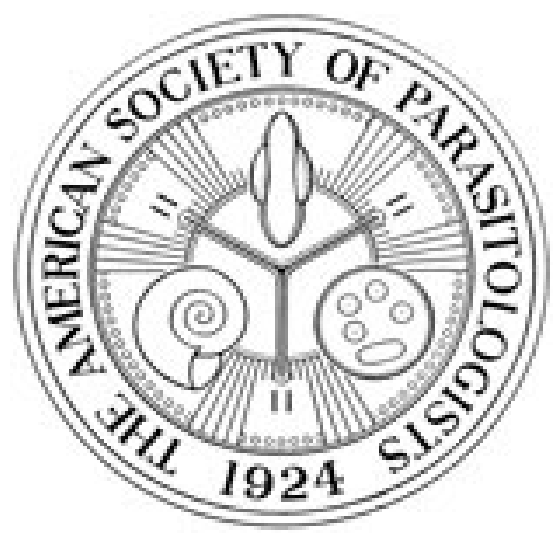

Vaccination of Mice with Neospora caninum: Response to Oral Challenge with Toxoplasma gondii Oocysts

Author(s): David S. Lindsay, Steve D. Lenz, Christine C. Dykstra, Byron L. Blagburn and J. P. Dubey

Source: The Journal of Parasitology, Vol. 84, No. 2 (Apr., 1998), pp. 311-315

Published by: The American Society of Parasitologists

Stable URL: http://www.jstor.org/stable/3284488

Accessed: 19/06/2014 10:38

Your use of the JSTOR archive indicates your acceptance of the Terms \& Conditions of Use, available at http://www.jstor.org/page/info/about/policies/terms.jsp

JSTOR is a not-for-profit service that helps scholars, researchers, and students discover, use, and build upon a wide range of content in a trusted digital archive. We use information technology and tools to increase productivity and facilitate new forms of scholarship. For more information about JSTOR, please contact support@jstor.org.

The American Society of Parasitologists is collaborating with JSTOR to digitize, preserve and extend access to The Journal of Parasitology. 


\title{
VACCINATION OF MICE WITH NEOSPORA CANINUM: RESPONSE TO ORAL CHALLENGE WITH TOXOPLASMA GONDII OOCYSTS
}

\author{
David S. Lindsay ${ }^{\star}$ Steve D. Lenz, Christine C. Dykstra, Byron L. Blagburn, and J. P. Dubey† \\ Department of Pathobiology, College of Veterinary Medicine, Auburn University, Auburn, Alabama 36849-5519
}

\begin{abstract}
Neospora caninum is a protozoan parasite that can cause severe disease in mammals. Two experiments were conducted to examine the effects of subcutaneous (s.c.) vaccination with Hank's balanced salt solution (HBSS), $1 \times 10^{5} \mathrm{~N}$. caninum NC-1 strain tachyzoites or $1 \times 10^{5}$ Toxoplasma gondii TS-4 strain tachyzoites on challenge oral infections in mice with sporulated VEG strain $T$. gondii oocysts $\left(1 \times 10^{3}\right.$ oocysts exp. 1 and $5 \times 10^{3}$ oocysts exp. 2$)$. An additional study, experiment 3 , evaluated s.c. challenge with $2.5 \times 10^{3}$ tachyzoites of the highly virulent RH strain of $T$. gondii after vaccination with HBSS, NC-1 tachyzoites, or TS-4 tachyzoites. Mice vaccinated with NC-1 strain tachyzoites survived significantly $(P<0.05)$ longer than mice given HBSS in experiment 1 , but not in experiments 2 and 3. Mice vaccinated with TS-4 strain tachyzoites survived significantly longer than HBSS-vaccinated mice in experiments 1,2 , and 3 and significantly longer than mice vaccinated with the NC-1 strain in experiments 2 and 3. Toxoplasma gondii tissue cyst numbers were significantly lower for mice vaccinated with TS-4 strain tachyzoites than mice vaccinated with HBSS or the NC-1 strain tachyzoites in experiment 1 . No difference was observed in tissue cyst numbers in mice vaccinated with HBSS or NC-1 strain tachyzoites in experiment 1 . No HBSS-vaccinated mice survived experiment 2 , and the numbers of $T$. gondii tissue cysts were significantly lower for mice vaccinated with the TS4 strain tachyzoites compared to NC-1 strain tachyzoites. No HBSS- or NC-1-vaccinated mice survived RH strain challenge in experiment 3. Results of these experiments indicate that infection with $N$. caninum provides some protection against fatal oral infection with $T$. gondii oocysts of a moderately pathogenic strain but not tachyzoites of a highly pathogenic strain. The protection provided by $N$. caninum is much less than that provided by previous exposure to $T$. gondii, and the numbers of tissue cysts in the brains of mice are not significantly $(P>00.5)$ lowered.
\end{abstract}

Neospora caninum is an apicomplexan parasite that was recognized as a cause of neuromuscular disease dogs in 1988 and subsequently determined to be a major cause of abortions in cattle (see Dubey and Lindsay, 1996). Neospora caninum is also associated with abortions and neonatal paralysis/disease in goats, sheep, black-tailed deer, Eld deer, and horses (see Dubey and Lindsay, 1996). Toxoplasma gondii, another important related parasite, is found in many animals that are susceptible to $N$. caninum infection.

We have previously demonstrated that outbred mice vaccinated subcutaneously (s.c.) with the NC-1 or NC-3 strains of $N$. caninum are not protected from fatal disease when s.c. challenged with tachyzoites of the highly virulent RH or GT-1 strains of $T$. gondii (Lindsay et al., 1990). The possibility exists that some cross protection may be present but overcome by the highly pathogenic strains of $T$. gondii used in our study.

The present studies were done to determine if prior $N$. caninum infection protects mice against fatal oral challenge with $T$. gondii oocysts of a moderately pathogenic strain, to determine if the numbers of $T$. gondii tissue cysts that are produced in $N$. caninum-infected mice are reduced compared to noninfected controls inoculated with oocysts, and to compare lesions in the brains of inoculated mice. Simultaneous studies were done with mice s.c. vaccinated with the nonpathogenic/nonpersistent TS-4 mutant (Waldeland and Frenkel, 1983) of T. gondii to compare relative protection afforded by $\mathrm{NC}-1$ vaccination and $T$. gondii vaccination against oral oocyst challenge with $T$. gondii. Additionally, we examined a 1 log lower s.c. challenge dose of the RH strain to determine if mice vaccinated with the

Received 27 August 1997; revised 12 November 1997; accepted 12 November 1997.

* Present address: Center for Molecular Medicine and Infectious Diseases, Department of Biomedical Sciences and Pathobiology, Virginia-Maryland Regional College of Veterinary Medicine, Virginia Tech, 1410 Prices Fork Road, Blacksburg, Virginia 24061-0342.

+ U.S. Department of Agriculture, Parasite Biology and Epidemiology Laboratory, BARC-East, Bldg. 1040, Beltsville, Maryland 20705.
NC-1 strain would survive a lower s.c. $T$. gondii infection than in our previous study (Lindsay et al., 1990).

\section{MATERIALS AND METHODS}

\section{Parasite strains}

Tachyzoites of the NC-1 strain (Dubey et al., 1988) of $N$. caninum and the RH strain (Sabin, 1941) and TS-4 strain (Pefferkorn and Pefferkorn, 1976) of $T$. gondii were grown separately in human foreskin fibroblast cells (Hs68, American Type Culture Collection, CRL 1635, Rockville, Maryland) at $37 \mathrm{C}$ (NC-1 and RH) or $32.5 \mathrm{C}$ (TS-4) in an incubator with $95 \%$ air $-5 \% \mathrm{CO}_{2}$ atmosphere as previously described (Lindsay et al., 1993). The NC-1 strain of $N$. caninum and the TS-4 strain of $T$. gondii are avirulent in outbred mice, whereas the RH strain of $T$. gondii is highly pathogenic for mice. To obtain tachyzoites for inoculations, the growth medium was removed from the flask and replaced with Hanks' balanced salt solution (HBSS). Cells containing tachyzoites were scraped from the plastic growth surface using a plastic cell scraper. The suspension was then filtered through a sterile $3-\mu \mathrm{m}$ filter and the numbers of tachyzoites present in the filtrate counted with the aid of a hemacytometer. The final volume of suspension was adjusted so that $0.5 \mathrm{ml}$ contained $1 \times 10^{5} \mathrm{NC}-1$ or TS- 4 strain and $2.5 \times$ $10^{3} \mathrm{RH}$ strain tachyzoites for s.c. inoculations. Control mice were inoculated s.c. with $0.5 \mathrm{ml}$ of HBSS.

Oocysts of the VEG strain (Parmley et al., 1994) of $T$. gondii were collected from the feces of experimentally infected cats (Dubey et al., 1996), sporulated in $2 \%(\mathrm{v} / \mathrm{v})$ sulfuric acid solution, washed free of acid in HBSS, and stored in HBSS at $4 \mathrm{C}$ until used. Bradyzoites and tachyzoites of the VEG strain are relatively nonpathogenic for outbred mice but oocysts are moderately pathogenic for outbred mice. Using a 22 -gauge animal feeding needle, mice were fed $0.5 \mathrm{ml}$ HBSS that contained $1 \times 10^{3}$ (experiment 1 ) or $5 \times 10^{3}$ (experiment 2 ) sporulated oocysts.

\section{Mouse inoculations}

Mice used were outbred HSD:ICR obtained from a commercial supplier (Harlan Sprague Dawley, Indianapolis, Indiana). Mice were 1822-g females and housed in groups in plastic box cages and provided rodent chow and water ad libitum. Mice used to bioassay for the NC1 strain of $N$. caninum only were given $4 \mathrm{mg}$ methylprednisolone acetate (MPA) intramuscularly on the day of inoculation to enhance the possibility of $N$. caninum isolation (Lindsay and Dubey, 1989). Other mice used in this study did not receive MPA.

Experiment 1 contained 4 groups of 10 mice each, experiment 2 
TABLE I. Protocols for inoculation and challenge of mice and results of mortality and mean survival time postchallenge of mice in experiments 1,2 , and 3 .

\begin{tabular}{|c|c|c|c|c|}
\hline $\begin{array}{l}\text { Experiment/ } \\
\text { group }\end{array}$ & $\begin{array}{l}\text { First/second } \\
\text { vaccination* }\end{array}$ & $\begin{array}{l}\text { Challenge } \\
\text { inoculation } \dagger\end{array}$ & $\begin{array}{c}\text { Mean challenge } \\
(\% \text { mortality }) \ddagger\end{array}$ & $\begin{array}{l}\text { Mean survival } \\
(\text { days } \pm \mathrm{SD}) \S\end{array}$ \\
\hline \multicolumn{5}{|l|}{ Experiment 1} \\
\hline $1 / 1$ & HBSS/HBSS & VEG/L & 80 & $21 \pm 19.1^{\mathrm{a}}$ \\
\hline $1 / 2 \|$ & NC-1/NC-1 & VEG/L & 11 & $54 \pm 5.0^{\mathrm{b}}$ \\
\hline $1 / 3$ & TS-4/TS-4 & VEG/L & 0 & $56 \pm 0.0^{\mathrm{b}}$ \\
\hline $1 / 4 \#$ & NC-1/NC-1 & None & 0 & NA \\
\hline \multicolumn{5}{|l|}{ Experiment 2} \\
\hline $2 / 1$ & HBSS/HBSS & VEG/H & 100 & $9 \pm 1.7^{\mathrm{a}}$ \\
\hline $2 / 2$ & NC-1/NC-1 & VEG/H & 70 & $23 \pm 22.7^{a}$ \\
\hline $2 / 3$ & TS-4/TS-4 & VEG/H & 20 & $47 \pm 19.8^{b}$ \\
\hline \multicolumn{5}{|l|}{ Experiment 3} \\
\hline $3 / 1$ & HBSS/HBSS & $\mathrm{RH}$ & 100 & $10 \pm 1.2^{\mathrm{a}}$ \\
\hline $3 / 2$ & NC-1/NC-1 & $\mathrm{RH}$ & 100 & $11 \pm 1.5^{\mathrm{a}}$ \\
\hline $3 / 3$ & TS-4/TS-4 & $\mathrm{RH}$ & 10 & $52 \pm 11.4^{\mathrm{b}}$ \\
\hline
\end{tabular}

* Vaccinations were subcutaneous (s.c.) and given on days 0 and 14 postinoculation $(\mathrm{PI})$. HBSS $=$ Hank's balanced salt solution; NC-1 $=1 \times 10^{5}$ tachyzoites of the NC-1 strain of Neospora caninum; TS-4 $=1 \times 10^{5}$ tachyzoites of the TS- 4 strain of Toxoplasma gondii.

+ Challenges were given orally $\left(\mathrm{VEG} / \mathrm{L}\right.$ and VEG/H) or s.c. $(\mathrm{RH})$ on day $28 \mathrm{PI}$. VEG/L $=1 \times 10^{3}$ VEG strain $T$. gondii oocysts; none $=$ nothing given; VEG/H $=$ $5 \times 10^{3}$ VEG strain $T$. gondii oocysts; $\mathrm{RH}=2.5 \times 10^{3} \mathrm{RH}$ strain $T$. gondii tachyzoites.

\# Percentage of mice that died during 56-day postchallenge (PC) period except for experiment 1 , group 4 , which was 64 days PC.

$\$$ Mean number of days that mice survived PC \pm standard deviation. Significant differences $(P<0.05)$ exist for groups with different alphabetical superscripts within an experiment.

\| Data are from 9 mice only.

\# Mice in this group were examined at necropsy 64 days PC. NA $=$ not applicable.

contained 3 groups of 10 mice each, and experiment 3 contained 3 groups of 10 mice each. The protocols for s.c. inoculations and oocyst feedings are given in Table I. Briefly, mice were s.c. inoculated with HBSS, NC-1, or TS-4 tachyzoites on days 0 (first vaccination) and 14 (second vaccination) postinoculation (PI). Mice were then challenged by feeding oocysts or HBSS, or by s.c. inoculation of RH strain tachyzoites or HBSS on day 28 PI. Blood was collected from the retro-orbital plexus of each mouse on day 28 PI and tested in an indirect immunofluorescent antibody test (IFAT, see below). The study was terminated on day 56 postchallenge (PC; 84 PI first inoculation) except for group 4 in experiment 1 that was inoculated with the $\mathrm{NC}-1$ strain and not challenged. This group was examined 64 days PC of groups 1-3. Additional groups of mice were used to bioassay for the presence of tissue cysts in mice that were negative at necropsy.

To determine the influence of vaccination on mouse survival time PC, the survival days PC were compared for each challenged group within an experiment using a Kruskal-Wallis nonparametric test and a distribution-free multiple comparisons method in experiment 1 and a Mann-Whitney $U$-test in experiment 2 (Zar, 1984). Significance was established at a cutoff of $P<0.05$ prior to analysis of the data.

\section{Necropsy examinations and tissue cyst determinations}

Lung, liver, or brain smears were made from the tissues of mice that died before the end of the study and examined unstained for tachyzoites or tissue cysts using bright-field microscopy. Surviving mice were bled from the retro-orbital plexus, killed, and examined at necropsy. The brain was removed from each mouse and the right side (cerebrum, cerebellum, etc.) fixed in $10 \%$ neutral buffered formalin. Tissue sections were obtained using routine histological techniques and stained with hematoxylin and eosin and used for microscopic lesion scoring (see below). The left side of the brain was placed in $2 \mathrm{ml}$ of HBSS, ground with 5 strokes of a teflon-coated tissue grinder, and the number of tissue cysts present in $50 \mu \mathrm{l}$ determined by counting using a bright-field microscope. If no tissue cysts were observed in the $50-\mu l$ sample then $1-$ $1.5 \mathrm{ml}$ of the homogenate was s.c. injected into an additional mouse, sera were collected, and the mouse was examined at necropsy 56 days PI. The numbers of tissue cysts present were evaluated using a KruskalWallis nonparametric test and a distribution-free multiple comparisons method in experiment 1 and a Mann-Whitney $U$-test in experiment 2
(Zar, 1984). Significance was established at a cutoff of $P<0.05$ prior to conduct of analysis of data.

\section{Lesion scores}

Hematoxylin- and eosin-stained tissue sections of brains were coded and brain lesions determined in a blinded fashion without knowledge of mouse treatment by 1 of the authors (S.D.L.). The brain lesions were scored based on the following 3 criteria: (1) number of inflammatory or necrotic foci, 0 foci $=$ grade $1,1-5$ foci $=$ grade $2,6-10$ foci $=$ grade $3,>10$ foci $=\operatorname{grade} 4 ;(2)$ mean size of foci, none $=$ grade 1 , $\leq 200 \mu \mathrm{m}=$ grade $2,201-500 \mu \mathrm{m}=\operatorname{grade} 3,>500 \mu \mathrm{m}=\operatorname{grade} 4$; and (3) severity of lesions, none $=$ grade 1 , slight $=$ grade 2 , mild $=$ grade 3 , moderate $=$ grade 4 , and marked $=$ grade 5 . The mean of these 3 values was determined and represented a mean lesion score. The numbers of mice in each treatment with lesions was examined using Fisher's exact test. Mean lesion scores were evaluated using a KruskalWallis nonparametric test and a distribution-free multiple-comparisons method in experiment 1 and a Mann-Whitney $U$-test in experiment 2 (Zar, 1984). Significance was established at a cutoff of $P<0.05$ prior to analysis of the data.

\section{Serology and western blotting}

Sera from days 28 PI (day 0 PC) and 56 PC (64 PC for experiment 1, group 4) were examined for IgG antibodies to $T$. gondii and $N$. caninum by an IFAT as previously described (Cole et al., 1995). Tachyzoites of each species were used separately as antigen and sera were endpoint titered by doubling dilutions beginning at a 1:50 dilution. Sera from mice used to bioassay for tissue cysts was examined only at a 1 : 50 dilution for both $T$. gondii and $N$. caninum. Only tachyzoites that demonstrated complete surface fluorescence were considered positive.

For western blotting studies, $4 \times 10^{5}$ freshly isolated tachyzoites of the RH strain of $T$. gondii or NC-1 strain of $N$. caninum were lysed by the addition of sodium dodecyl sulfate (SDS) gel sample buffer and heating for $10 \mathrm{~min}$ at $95 \mathrm{C}$. The samples were applied to a $10 \% \mathrm{SDS}-$ polyacrylamide gel electrophoresis (PAGE) gel and after electrophoresis were transferred to Immobilon membranes using an electrotransfer apparatus (BioRad, Hercules, California). Filters were rinsed in tris-buffered saline (TBS) and unreacted areas blocked by incubation in $2 \%$ 
(w/v) bovine serum albumin (BSA) in TBS (BSA/TBS) for $2 \mathrm{hr}$ at room temperature $(21-23 \mathrm{C})$. The filters were then placed in a multiscreen apparatus (BioRad) and incubated for $1 \mathrm{hr}$ at room temperature in mouse serum diluted in TBS. The mouse serum was used at a dilution equlivant to its IFA titer. Fiters were washed once for $5 \mathrm{~min}$ in the apparatus in TBS and then removed and washed 3 times in $0.2 \%(\mathrm{w} / \mathrm{v})$ BSA/TBS for $5 \mathrm{~min}$ each. The filters were then incubated in alkaline phosphatase-conjugated goat anti-mouse IgG diluted 1:3,000 in TBS for $1 \mathrm{hr}$ at room temperature. Filters were washed 3 times for $5 \mathrm{~min}$ in TBS and once in alkaline phosphatase buffer before the reactive bands were visualized by development in nitroblue tetrazolium/BCIP buffer. After the bands became visible, the reaction was stopped by addition of acetic acid to $10 \%(\mathrm{v} / \mathrm{v})$ and the filters washed in water and air dried before examination.

\section{RESULTS}

\section{Experiment 1}

The mice inoculated s.c. with HBSS (group 1-1) or TS-4 tachyzoites (group 1-3) did not develop clinical signs prior to oocyst challenge. One mouse in group 2 inoculated with NC-1 tachyzoites developed a head tilt on day 27 PI. Another mouse in group 2 had a swelling on its dorsal surface (indicative of abscess formation) first noticed 28 days PI. This mouse died 4 days PC with oocysts and was too autolytic for examination. It was concluded the mouse died from bacterial infection, and it was removed from the study. Therefore, only 9 mice were included in the analysis of data from group 1-2 mice. None of the mice inoculated with NC-1 strain tachyzoites in group 4 developed clinical signs. Eight of the group 1-1 HBSS-inoculated mice died between 8 and 12 days PC; 1 mouse in group 1-2 NC-1 inoculated died 41 days PC, and none of the mice in groups 1-3 or 1-4 died during the 56-day PC period. Stages of $T$. gondii were observed in smears from all mice that died and were examined. Results of mean survival days are presented in Table I. Challenged mice in groups 1-2 and 1-3 survived significantly longer than challenged mice in group 1-1.

Results of mean lesion scores and tissue cyst counts for mice in experiment 1 are presented in Table II. The mean lesion scores were significantly higher for mice vaccinated with HBSS or NC-1 strain tachyzoites and challenged with oocysts compared to mice vaccinated with the TS- 4 strain and challenged with oocysts. The mean lesion scores of mice vaccinated with the NC-1 strain tachyzoites and not challenged with oocysts were significantly lower than mice vaccinated with HBSS or NC-1 strain tachyzoites and challenged with oocysts but not the TS-4-vaccinated oocyst-challenged mice. All tissue cysts observed in brain homogenates were thin-walled and considered to be $T$. gondii. All surviving mice in groups 1-1 (HBSS vaccinated) and 1-2 (NC-1 vaccinated) had tissue cysts. No $T$. gondii tissue cysts were observed in 7 of 10 mice in group 1-3 given TS-4 tachyzoites and fed VEG oocysts. All 7 had antibodies to $T$. gondii in their sera, and subinoculation of brain homogenate from these 7 mice indicated that all contained $T$. gondii tissue cysts. The numbers of $T$. gondii tissue cysts were significantly higher in mice in group 1-1 and group 1-2 than group 1-3. No significant difference was observed in the numbers of $T$. gondii tissue cysts in mice in groups 1-1 or 1-2. No tissue cysts ( $N$. caninum-like or $T$. gondii-like) were observed in the 10 mice in group $1-4$ given only NC-1 tachyzoites. One mouse died 33 days PI of brain homogenate and had lesions suggestive of neosporosis in tissue sections of brain. Three of the 9 other mice inoculated with brain homogenate were positive for $N$. caninum antibodies at a 1:50 dilution of serum.

Mice in group 1-1 did not have demonstrable IgG antibodies to $T$. gondii or $N$. caninum in the IFAT 28 days PI; the 2 surviving mice had IFAT titers of $1: 12,800$ and $1: 25,600$ to $T$. gondii but did not have IFAT titers to $N$. caninum 56 days PC. Mice in group 1-2 did not have demonstrable IFAT titers to $T$. gondii 28 days PC and had IFAT titers of $1: 800$ to $1: 3,200$ to $N$. caninum. The 8 surviving mice had IFAT titers of $1: 3,200$ to $1: 25,600$ to $T$. gondii and $1: 200$ to $1: 800$ to $N$. caninum 56 days PC. Mice in group 1-3 did not have demonstrable IFAT

TABLE II. Microscopic lesion scores and Toxoplasma gondii tissue cyst counts of mice in experiments 1 and 2 .

\begin{tabular}{|c|c|c|c|c|c|}
\hline $\begin{array}{c}\text { Experiment/ } \\
\text { group }\end{array}$ & $\begin{array}{c}1 \mathrm{st} / 2 \mathrm{nd} \\
\text { vaccination* }\end{array}$ & $\begin{array}{l}\text { Challenge } \\
\text { inoculation }\end{array}$ & $\begin{array}{c}\text { No. exam/ } \\
\text { no. lesions } \ddagger\end{array}$ & $\begin{array}{c}\text { Mean } \\
\text { lesion score }\end{array}$ & $\begin{array}{c}\text { Mean } \\
\text { tissue cyst } \\
\text { counts } \pm \mathrm{SD} \|\end{array}$ \\
\hline \multicolumn{6}{|l|}{ Experiment 1} \\
\hline $1 / 1$ & HBSS/HBSS & VEG/L & $2 / 2^{\mathrm{a}}$ & $10.0^{\mathrm{a}}$ & $77 \pm 32^{\mathrm{a}}$ \\
\hline $1 / 2$ & $\mathrm{NC} / \mathrm{NC}$ & VEG/L & $8 / 8^{a}$ & $8.1^{\mathrm{a}}$ & $74 \pm 26^{a}$ \\
\hline $1 / 3$ & TS/TS & VEG/L & $10 / 1^{b}$ & $3.3^{\mathrm{b}}$ & $2 \pm 3^{b}$ \\
\hline $1 / 4$ & $\mathrm{NC} / \mathrm{NC}$ & None & $10 / 3^{b}$ & $4.2^{\mathrm{b}}$ & NA\# \\
\hline \multicolumn{6}{|l|}{ Experiment 2} \\
\hline $2 / 1$ & HBSS/HBSS & VEG/H & NA/NA & NA & NA \\
\hline $2 / 2$ & $\mathrm{NC} / \mathrm{NC}$ & VEG/H & $3 / 3^{a}$ & $9.0^{\mathrm{a}}$ & $71 \pm 31^{a}$ \\
\hline $2 / 3$ & $\mathrm{TS} / \mathrm{TS}$ & VEG/H & $8 / 3^{a}$ & $4.5^{\mathrm{b}}$ & $14 \pm 10^{b}$ \\
\hline \multicolumn{6}{|c|}{ 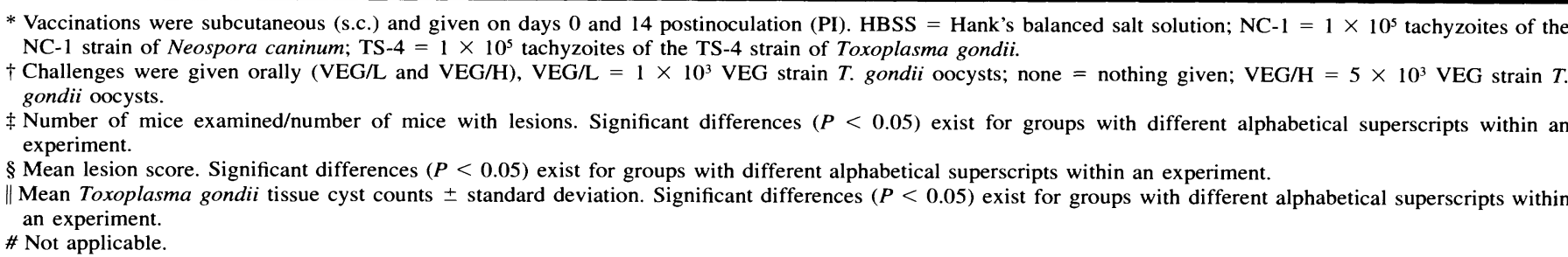 } \\
\hline
\end{tabular}


titers to $N$. caninum 28 days PC and had IFAT titers of 1:800 to $1: 12,800$ to $T$. gondii. The 10 surviving mice did not have IFAT titers to $N$. caninum and had titers of $1: 12,800$ to $1: 25,600$ to $T$. gondii 56 days PC. Mice in group 1-4 did not have IFAT titers to $T$. gondii 28 days PI or 64 days PC and had titers of $1: 800$ to $1: 3,200$ to $N$. caninum 28 days PI and titers of $1: 200$ to $1: 1,600$ at 64 days PC.

\section{Experiment 2}

No clinical signs were noted in mice in experiment 2 prior to feeding of VEG oocysts. The group 2-1 HBSS control mice died 7-12 days after feeding of oocysts. Seven of 10 group 22 NC-1-vaccinated mice died 9-11 days PI and the remaining 3 survived for 56 days. Two of the group 2-3 TS-4-vaccinated mice died 9 days PI and the remaining 8 survived for 56 days. Results of mean survival days are presented in Table I. No difference in survival days were present in mice vaccinated with HBSS or NC-1 strain tachyzoites, but both were significantly lower than the mice vaccinated with the TS-4 strain and challenged with oocysts.

Results of mean lesion scores and tissue cyst counts for mice in experiment 2 are presented in Table II. Lesion scores were not obtained from mice in group 2-1 because they all died before the end of the study. Mice vaccinated with the NC-1 strain tachyzoites and fed oocysts had significantly higher lesions scores compared to mice vaccinated with TS-4 strain tachyzoites and fed oocysts. All tissue cysts observed in brain homogenates were thin-walled and considered to be $T$. gondii. All surviving mice in groups 2-2 (NC-1 vaccinated) and 2-3 (TS4 vaccinated) had tissue cysts, and the mice in group 2-2 had significantly more tissue cysts than did the mice in group 2-3.

Mice in group 2-1 did not have demonstrable $\mathrm{IgG}$ antibodies to $T$. gondii or $N$. caninum in the IFAT 28 days PI. Mice in group 2-2 did not have demonstrable IFAT titers to $T$. gondii 28 days PC and had IFAT titers of $1: 100$ to $1: 1,600$ to $N$. caninum. The 3 surviving mice had IFAT titers of $1: 1,600$ to 1 : 3,200 to $T$. gondii and $1: 400$ to $1: 800$ to $N$. caninum 56 days PC. Mice in group 2-3 did not have demonstrable IFAT titers to $N$. caninum 28 days $\mathrm{PC}$ and had titers of $1: 100$ to $1: 400$ to $T$. gondii. The 8 surviving mice did not have IFAT titers to $N$. caninum and had IFAT titers of $1: 800$ to $1: 6,400$ to $T$. gondii 56 days $\mathrm{PC}$.

\section{Experiment 3}

No clinical signs were noted in mice in experiment 3 prior to challenge inoculations with RH tachyzoites. The group 3-1 HBSS control mice died 7-11 days PC with tachyzoites. All 10 of the group 3-2 NC-1-vaccinated mice died 9-14 days PC. One of the group 3-3 TS-4-vaccinated mice died 20 days PC and the remaining 9 survived for 56 days. Two of the 9 mice in group 3-3 had lesions and the mean lesion score was 3.8. No tissue cysts were observed in the brains of the 9 surviving mice in group 3-3. Infectious stages of the RH strain of $T$. gondii were present in 6 of 9 of the surviving mice in group 3-3; subinoculation of brain homogenate from these mice produced mortalities in 5 mice 14-27 days PI and 1 mouse survived for 56 days. Tissue cysts were observed in brain smears from this mouse, and a mouse inoculated with brain homogenate from this mouse died from toxoplasmosis 16 days PI.
Mice in group 3-1 vaccinated with HBSS did not have IFAT titers to $N$. caninum or $T$. gondii 28 days PI and none survived the challenge with RH strain tachyzoites. Mice in group 3-2 vaccinated with NC-1 strain tachzyoites had IFAT titers of 1 : 800 to $1: 6,400$ to $N$. caninum but did not have IFAT titers to T. gondii 28 days PI, and none survived the challenge with RH strain tachyzoites. Mice in group 3-3 vaccinated with TS-4 strain tachzyoites did not have IFAT titers to $N$. caninum but had IFAT titers of $1: 100$ to $1: 800$ to $T$. gondii 28 days PI. The 9 surviving mice did not have IFAT titers to $N$. caninum but had IFAT titers of $1: 3,200$ to $1: 12,500$ to $T$. gondii at 56 days PC.

\section{Western blot analysis}

Sera from mice not vaccinated did not produce reactions in western blots to tachyzoites of either $N$. caninum or $T$. gondii. Sera from mice vaccinated with $N$. caninum recognized numerous peptides in western blots of $N$. caninum tachyzoites, but no or inconsistant reactivity was observed with tachyzoites of $T$. gondii. Sera from mice vaccinated with $T$. gondii recognized numerous peptides in western blots of $T$. gondii tachyzoites but no or inconsistant reactivity was observed with tachyzoites of N. caninum.

\section{DISCUSSION}

The present study indicates that vaccination with $N$. caninum can increase the survival time for mice fed oocysts of a moderately pathogenic strain of $T$. gondii. The mechanism of this induced protection is not known. Humoral antibodies do not appear to play an important role because none of the NC-1vaccinated mice had demonstrable serum $\operatorname{IgG}$ antibodies to $T$. gondii in the IFAT.

There is little consensus on cross-reactive antigens recognized by $N$. caninum antiserum on $T$. gondii tachyzoites and $T$. gondii antiserum on $N$. caninum tachyzoites in western blot analysis of animal sera (Bjerkås et al., 1994; Björkman et al., 1994; Paré et al., 1995; Baszler et al., 1996). Bjerkås et al. (1994) found that rabbit $N$. caninum antisera recognized antigens of 45,66 , and $85 \mathrm{kDa}$ on $T$. gondii tachyzoites, whereas rabbit $T$. gondii antisera recognized antigens of 46,88 , and 97 $\mathrm{kDa}$ on $N$. caninum tachyzoites. Björkman et al. (1994) found that rabbit $T$. gondii antisera recognized a $40-\mathrm{kDa}$ antigen on $N$. caninum tachyzoites. Paré et al. (1995) did not find reactivity of bovine $N$. caninum antisera with $T$. gondii proteins in western blots. Baszler et al. (1996) found that bovine T. gondii antisera recognized $N$. caninum tachyzoite antigens that ranged from 11 to $80 \mathrm{kDa}$ if a 1:100 serum dilution was used, but that if a 1:10,000 dilution was used, then only $N$. caninum tachyzoite antigens of 14 and $37 \mathrm{kDa}$ were recognized.

Cell-mediated immunity is likely to be involved in the protection observed in $N$. caninum-vaccinated mice and may be stimulated in some nonspecific manner by vaccination. Khan et al. (1997) have shown that splenocytes from mice inoculated with the NC-1 strain of $N$. caninum will undergo proliferation in response to soluble $T$. gondii (strain PLK) lysates. The host response responsible for prolonging the survival of NC-1-vaccinated $T$. gondii-challenged mice does not appear to influence $T$. gondii tissue cyst formation because tissue cyst numbers were not significantly different from nonvaccinated controls. 
Mouse and $T$. gondii strain are known to influence tissue cyst production and resistance to primary $T$. gondii infection in inbred mice (Suzuki et al., 1989, 1991, 1993; Brown and McLeod, 1990; Blackwell et al., 1993).

No protection was provided from s.c. challenge with the RH strain of $T$. gondii in $N$. caninum-vaccinated mice. This is identical to our previous findings (Lindsay et al., 1990) and was obtained with a log lower dose of RH strain tachyzoites used as challenge inoculum.

\section{ACKNOWLEDGMENTS}

This study was supported in part by grant FADHR-ALAV0270, College of Veterinary Medicine, Auburn University. We thank M. A. Cheadle for technical assistance.

\section{LITERATURE CITED}

Baszler, T. V., D. P. Knowles, J. P. Dubey, J. M. Gay, B. A. Mathison, AND T. F. MCELwaIN. 1996. Serological diagnosis of bovine neosporosis by Neospora caninum monoclonal antibody-based competitive inhibition enzyme-linked immunosorbent assay. Journal of Clinical Microbiology 34: 1423-1428.

BJERKÅS, I., M. C. JENKINS, AND J. P. DUBEY. 1994. Identification and characterization of Neospora caninum tachyzoite antigens useful for diagnosis of neosporosis. Clinical and Diagnostic Laboratory Immunology 1: 214-221.

BJörkman, C., A. LundÉn, J. Holmdahl, J. Barber, A. J. Trees, AND A. UgGla. 1994. Neospora caninum in dogs: Detection of antibodies by ELISA using an iscom antigen. Parasite Immunology 16: 643-648.

Blackwell, J. M., C. W. Roberts, and J. Alexander. 1993. Influence of genes within the MHC on mortality and brain cyst development in mice infected with Toxoplasma gondii: Kinetics of immune regulation in BALB H-2 congenic mice. Parasite Immunology 15: 317-324.

BRown, C., AND R. MCLEOD. 1990. Class I MHC genes and CD8 ${ }^{+} \mathrm{T}$ cells determine cyst number in Toxoplasma gondii infection. Journal of Immunology 145: 3438-3441.

Cole, R. A., D. S. Lindsay, B. L. Blagburn, and J. P. Dubey. 1995. Vertical transmission of Neospora caninum in mice. Journal of Parasitology 81: 730-732.

Dubey, J. P., A. L. HatTel, D. S. Lindsay, AND M. J. Topper. 1988. Neonatal Neospora caninum infection in dogs: Isolation of the causative agent and experimental transmission studies. Journal of the American Veterinary Medical Association 193: 1259-1263.

-, AND D. S. LINDSAY. 1996. A review of Neospora caninum and neosporosis. Veterinary Parasitology 67: 1-59.

-, J. K. LunNEY, S. K. Shen, O. C. H. KwOK, D. A. AshFord, AND P. THULLIEZ. 1996. Infectivity of low numbers of Toxoplasma gondii oocysts for pigs. Journal of Parasitology 82: 438-443.

Khan, I. A., J. D. Schwartzman, S. Fonseka, AND L. H. KaSPer. 1997. Neospora caninum: Role for immune cytokines in host immunity. Experimental Parasitology 85: 24-34.

Lindsay, D. S., B. L. BLAGBuRn, AND J. P. Dubey. 1990. Infection in mice with Neospora caninum (Protozoa: Apicomplexa) does not protect against challenge with Toxoplasma gondii. Infection and Immunity 58: $2699-2700$.

—_ AND J. P. Dubey. 1989. Neospora caninum (Protozoa: Apicomplexa) infections in mice. Journal of Parasitology 75: 722-779.

, C. A. SPeER, M. A. Toivio-Kinnucan, J. P. Dubey, AND B. L. BLAGBURN. 1993. Use of infected cultured cells to compare ultrastructural features of Neospora caninum from dogs with Toxoplasma gondii. American Journal of Veterinary Research 54: 103-106.

Paré, J., S. K. Hietala, and M. C. Thurmond. 1995. An enzymelinked immunosorbent assay (ELISA) for serological diagnosis of Neospora sp. infection in cattle. Journal of Veterinary Diagnostic Investigation 7: 352-359.

Parmley, S. F., U. Gross, A. Suchaarczuk, T. Windeck, G. D. SgarLATO, AND J. S. REMINGTON. 1994. Two alleles of the gene encoding surface antigen p22 in 25 strains of Toxoplasma gondii. Journal of Parasitology 80: 293-301.

Pefferkorn, E. R., AND L. C. PefFerkoRn. 1976. Toxoplasma gondii: Isolation and preliminary characterization of temperature sensitive mutants. Experimental Parasitology 39: 365-376.

SABIN, A. B. 1941. Toxoplasmic encephalitis in children. Journal of the American Medical Association 116: 801-807.

SUZUKI, Y., F. K. Conley, AND J. S. Remington. 1989. Differences in virulence and development of encephalitis during chronic infection vary with the strain of Toxoplasma gondii. Journal of Infectious Diseases 159: 790-794.

- K. Joh, M. A. Orellana, F. K. Conley, and J. S. Remington. 1991. A gene(s) within the H-2D region determines the development of toxoplasmic encephalitis in mice. Immunology 74: 732739.

A. Orellana, S. Wong, F. C. Conley, and J. S. Remington. 1993. Susceptibility to chronic infection with Toxoplasma gondii does not correlate with susceptibility to acute infection in mice. Infection and Immunity 61: 2284-2288.

Waldeland, H., AND J. K. FRENKel. 1983. Live and killed vaccines against toxoplasmosis in mice. Journal of Parasitology 69: 60-65.

ZAR, J. H. 1984. Biostatistical analysis, 2nd ed. Prentice Hall, Englewood Cliffs, New Jersey, 718 p. 